\title{
A bioinformatics-based functional analysis shows that the specifically androgen-regulated gene SARG contains an active direct repeat androgen response element in the first intron
}

\author{
Karine Steketee, Angelique C J Ziel-van der Made, Hetty A G M van der Korput, \\ Adriaan B Houtsmuller and Jan Trapman
}

Department of Pathology, Josephine Nefkens Institute, Erasmus Medical Center, PO Box 1738, 3000 DR Rotterdam, The Netherlands

(Requests for offprints should be addressed to J Trapman; Email: j.trapman@erasmusmc.nl)

\begin{abstract}
We characterized the specifically androgen-regulated gene (SARG), which is expressed in the androgen receptor (AR) and glucocorticoid receptor (GR) positive cell line lymph node carcinoma of the prostate-1F5 (LNCaP-1F5). SARG mRNA expression can be up-regulated by androgens, but not by glucocorticoids. SARG mRNA expression is high in prostate tissue. SARG is composed of four exons and spans a region of $14.5 \mathrm{kbp}$ on chromosome 1q32.2. Transcripts of 5.5, 3.3 and $2.3 \mathrm{~kb}$ are the result of alternative polyadenylation. SARG mRNA splice variants lack exon 2 and vary in length of exon 1 . The SARG protein has a length of 601 amino acids and is located in the cytoplasm. By screening the $18 \mathrm{kbp}$ genomic sequence flanking the transcription start site we identified the imperfect direct repeat $5^{\prime}$-TGTGCTaacTGTTCT-3' in intron 1 as an active androgen response element (ARE-SARG+4.6). A 569 bp genomic DNA fragment containing this element functioned as an androgen-specific enhancer in transiently transfected LNCaP-1F5 cells. ARE-SARG +4.6 cooperated with flanking sequences for optimal activity. Inactivation of ARE-SARG+4.6 completely abolished the androgen response of the enhancer. Chromatin immunoprecipitation (ChIP) experiments showed chromatin structural changes of the enhancer in the presence of R1881. ARE-SARG+4.6 was able to bind to the androgen receptor, but not to the glucocorticoid receptor, correlating with its androgen-specific activity in transfections.
\end{abstract}

Journal of Molecular Endocrinology (2004) 33, 477-491

\section{Introduction}

Androgens are essential in the development and maintenance of the male phenotype. They mediate their function by activation of the androgen receptor (AR), which is a member of the nuclear receptor family of ligand-activated transcription factors. Nuclear receptors have a modular structure composed of a moderately conserved carboxylterminal ligand-binding domain (LBD), a highly conserved central DNA-binding domain (DBD) and a non-conserved amino-terminal domain (NTD). Most ligand-activated nuclear receptors bind as homodimers or heterodimers to hormone response elements (HREs) in the regulatory regions of their target genes. HREs are composed of an inverted or direct repeat of two $6 \mathrm{bp}$ half-sites separated by a spacer of variable size (Khorasanizadeh \& Rastinejad 2001). Together with coactivators, chromatin remodelling complexes, general transcription factors and RNA polymerase II, nuclear receptors initiate the transcription of target genes in a tightly controlled fashion (Glass \& Rosenfeld 2000, Lee \& Lee Kraus 2001, McKenna \& O’Malley 2002).

An important class of nuclear receptors is the family of steroid hormone receptors, which is composed of AR, glucocorticoid receptor (GR), mineralocorticoid receptor (MR), progesterone receptor $(\mathrm{PR})$ and estrogen receptors alpha and beta (ER $\alpha$ and ER $\beta$ ) (Thornton 2001). Steroid hormone receptors display distinct physiological functions, reflected in their tissue-specific expression pattern and to some extent in their spectrum 
of target genes. However, AR, GR, MR and PR all bind with high affinity to the same inverted repeat consensus sequence 5'-AGAACAnnnTGTTCT-3' (Nordeen et al. 1990, Roche et al. 1992, Lieberman et al. 1993, Lombes et al. 1993). As a result, the activity of several promoters can be regulated by more than one of these receptors. Examples are the MMTV promoter, and the promoters of the C3, the cystatin-related protein (CRP) and the prostate specific antigen (PSA) gene (Ham et al. 1988, Claessens et al. 1989, De Vos et al. 1994, Cleutjens et al. 1997, Devos et al. 1997). The consensus high affinity binding site of $\operatorname{ER} \alpha$ and $\operatorname{ER} \beta$ is slightly different, 5'-AGGTCAnnnTGACGT-3' (KleinHitpass et al. 1989), therefore ER $\alpha$ and ER $\beta$ direct the expression of a different panel of target genes. Because GR, MR, PR and AR recognize the same DNA sequence, it has been postulated that additional mechanisms are necessary to explain their specificity. These include differences in expression levels of the various receptors in specific cell types (Strahle et al. 1989), selective interaction with specific transcription factors, coactivators and corepressors and ligand availability (Glass \& Rosenfeld 2000, Aranda \& Pascual 2001, Heinlein \& Chang 2002).

In spite of the identical high-affinity recognition sequence for $\mathrm{AR}, \mathrm{PR}, \mathrm{GR}$ and $\mathrm{MR}$, steroid response elements can also direct receptor specificity. In natural promoters steroid receptor binding sites can deviate considerably from the consensus high-affinity binding site. These sequences might have a different affinity to the various receptors. Additionally, sequences directly flanking the response element can contribute to receptor affinity and preference (Nelson et al. 1999, Haelens et al. 2003). On top of this, the AR seems to have adopted an exclusive mechanism of specificity. A few genes are known to be preferentially regulated by AR (Claessens et al. 2001). The structures of the androgen response elements (AREs) that direct androgen-specificity to these genes resemble more direct repeats of the sequence $5^{\prime}$-TGTTCT- $3^{\prime}$ than classic inverted repeats of this sequence.

The androgen-sensitive human prostate carcinoma cell line, lymph node carcinoma of the prostate (LNCaP) expresses AR, but lacks GR and PR (Horoszewicz et al. 1983, Berns et al. 1986). It was previously shown that growth of LNCaP cells and PSA mRNA expression in these cells can be stimulated by androgens (Schuurmans et al. 1988,
Riegman et al. 1991, Young et al. 1991). In order to directly compare the molecular and biological function of AR and GR, the LNCaP-1F5 subline, containing a stably integrated GR expression vector, was generated (Cleutjens et al. 1997). PSA mRNA expression in LNCaP-1F5 can be induced by both androgens and glucocorticoids but cell growth is selectively induced by androgens. We identified in LNCaP-1F5 cells a novel gene that is specifically regulated by androgens (Cleutjens et al. 1997). In the present study an integrated experimental and bioinformatics-based approach was applied to characterize the gene, designated specifically androgen-regulated gene (SARG), and to decipher the molecular mechanism of androgen-specific regulation of the gene.

\section{Materials and methods}

\section{Materials}

Methyltrienolone (R1881) was purchased from NEN (Boston, MA, USA), dexamethasone (Dex) was obtained from Steraloids (Wilton, NH, USA). Cell culture media were from Bio Whittaker (Verviers, Belgium), fetal calf serum (FCS) was from Roche Diagnostics (Almere, The Netherlands).

\section{Plasmid construction}

pLUG and pPSA-4-LUG have been described previously (Cleutjens et al. 1996). pHisXpresscSARG, expressing (His) ${ }_{6}$-Xpress-SARG protein, contains the SARG cDNA fragment 209-2579 (SARG ORF is from 251 to 2053) inserted in the eukaryotic expression vector pcDNA3.1 His (Invitrogen, Carlsbad, CA, USA).

The $S A R G$ genomic fragments $\mathrm{SARG}-8 \cdot 5$, $\mathrm{SARG}-7 \cdot 3$ and $\mathrm{SARG}+4 \cdot 6$, with sizes of $510 \mathrm{bp}$, $476 \mathrm{bp}$ and $569 \mathrm{bp}$ respectively, were obtained by PCR on PAC90 L18 DNA (GenomeSystems, St Louis, MO, USA) as template with the primer sets: - 8.5F: 5'-GATCAGCTGGATCGCAGGGA CATGGATGAAGCTG-3'; - 8.5R: 5'-GATGAG TGGATCGTGCGTCAACGTCGCAAGTAG-3'; - 7·3F: 5'-GATGAGCTGGATGGGTGATAAT GACTTGGCGATG-3'; - 7•3R: 5'-GATCAGCT GGATCGTGTCGAACATTTGAGGGCAG-3'; +4.6F: 5'-GATCAGCTGGATGGGTATCGTAG CGGTGGTTGTG-3' and +4.6R: 5'-GATCAGC TGGATCGTGGAGAGGGAGTCTAGTCAG-3’ . 
The resulting amplified fragments were inserted in pGEM-T Easy (Promega, Madison, WI, USA), sequenced and subsequently inserted as BamHI/ BamHI fragments in pPSA-4-LUC, yielding pSARG - 8.5-PSA-LUG, pSARG - 7.3-PSALUG and pSARG +4.6-PSA-LUG respectively.

The -55 to +168 genomic fragment SARG-S was obtained by PCR on PAC90 L18 DNA (GenomeSystems), utilizing the primers SARG-A: 5'-GCTAAGAGGGAACAGCACGAC-3' and SARG-B: 5'-CGCGGGAGATCTACTAGTCGA CTGGGTTG-3'. The PGR product was inserted in pGEM-T Easy (Promega), verified by sequencing and inserted as a $240 \mathrm{bp}$ PvuII/BglII fragment in pLUC, yielding pSARG-S-LUC. To generate pSARG-L-LUG, the -3012 to -1559 HindIII/ PvuII SARG genomic fragment was isolated from PAC90 L18 and inserted in the corresponding sites of pSARG-S-LUC, yielding pSARG-L $\Delta$-LUC. Subsequently, the -1559 to $-55 \mathrm{PvuII} / \mathrm{PvuII}$ genomic $S A R G$ fragment was inserted into the PvuII site of pSARG-L $\Delta$-LUC. The resulting construct pSARG-L-LUC contains SARG bp -3012 to +168 .

$\mathrm{SARG}+4.6$ was inserted as a BamHI/BamHI fragment upstream of the SARG-S promoter or SARG-L promoter in pSARG-S-LUG and pSARG-L-LUC respectively, yielding pSARG +4.6-SARG-S-LUC and pSARG + 4.6-SARG-LLUG. pSARG $+4 \cdot 6$ m-SARG-S-LUG was generated by mutagenesis utilizing the QuikChange Site Directed Mutagenesis Kit (Stratagene, LaJolla, CA, USA) using pSARG+4.6-SARG-S-LUC as template, primer mut-4603S: 5'-CAACTAAACTAT GATAACTATTATGTCATTTAATG-3' and its complementary strand, mut-4603AS.

SARG + 4.6- $-(+4447 /+4659)-$ S-LUG and SARG $+4 \cdot 6-(+4548 / 4659)-$ S-LUC were constructed by insertion of the respective BamHI/BamHI fragments upstream of the $\mathrm{S}$ promoter in pSARG-SLUC. The fragments SARG +4·6- $(+4447 /+4659)$ and SARG $+4 \cdot 6-(+4548 /+4659)$ were generated by PGR utilizing the primers $\mathrm{S}+4 \cdot 6-\mathrm{A}$ (5'-GAT CAGCTGGATCGCGTTGTTTTGTGAGATCG TG-3') and S+ 4.6-B (5'-GATCAGGTGGATCG GTCATGAGGTCTTAGGGTAT-3') as respective forward primers, and $\mathrm{S}+4 \cdot 6-\mathrm{C}$ (5'-GATCAG ATGGATCGGGCAAATTACTCTGAGTCTG-3') as reverse primer. Amplified fragments were sequenced prior to insertion into pSARG-S-LUG as BamHI/BamHI fragments.
pRIT2 TAR, encoding rat AR DBD, was described previously (De Vos et al. 1991). prGR-DBD-PRIT2T, encoding rat GR DBD, was constructed by BamHI/SalI insertion of a PGR fragment, synthesized with primers rGR-DBD-1: 5'-CAGGGGATCGGCAGCGACGGGACGACG TCGC-3' and rGR-DBD-2: 5'-CTATTGTCGA CTAAGGATTTTCGGAAGTGTCTTG-3' on pSTC-GR3-795 (Rusconi \& Yamamoto 1987) as template, in pRIT2T (Amersham Biosciences, Bucks, UK).

\section{Screening of a prostate cDNA library}

Screening of a $\lambda$ gt 10 human prostate cDNA library (BD Biosciences Clontech, Palo Alto, CA, USA) was performed according to the manufacturer's protocol. Hybridization probes were the SARG differential display PCR (DD-PCR) fragment (GenBank accession Number AF007835) and SARG cDNA fragment 855-1957 (see GenBank accession Number AY352640).

\section{RACE-PCR}

For RACE-PGR we applied the Marathon-Ready prostate cDNA cloning kit (BD Biosciences Clontech), primer SARG-RACE: 5'-CGTGAAG TTCTGGCTTGTGGGAATGTG-3' and the standard AP1 primer of the kit. Amplified cDNA fragments were inserted in pGEM-T Easy and sequenced.

\section{Analysis of alternative splicing of mRNA by RT-PCR}

cDNA was synthesized from $1 \mu \mathrm{g}$ total RNA isolated from LNCaP cells incubated for $24 \mathrm{~h}$ in RPMI 1640 supplemented with 5\% (v/v) dextrancoated charcoal treated FCS (FCS-DCG), antibiotics and $1 \mathrm{nM}$ R1881. cDNA synthesis was performed at $55^{\circ} \mathrm{C}$ utilizing M-MuLV reverse transcriptase and an oligo-dT primer. Subsequently, PCR was carried out under standard conditions on the LNCaP cDNA template utilizing either forward primer SARG-F1A: 5'-CGAGGCA GCACAGATGAAGC-3' or SARG-F1B: 5'-AGC CTCTGTCTCGATCTCTGG-3' in combination with the reverse primer SARG-R: 5'-CTTCAG TGGACAGGAAGTCG-3'. RT-PGR products were inserted in pGEM-T Easy and sequenced. 


\section{RNA isolation and Northern analysis}

Total RNA from LNCaP and LNCaP-1F5 cells was isolated by the guanidinium thiocyanate method (Sambrook \& Russell 2001). RNA (10 $\mu \mathrm{g}$ per lane) was separated by electrophoresis on a $1 \%$ (w/v) agarose formaldehyde gel in TBE. Following electrophoresis RNA was transferred to a Hybond- ${ }^{+}$membrane (Amersham Biosciences). The blot was hybridized under standard conditions at $65{ }^{\circ} \mathrm{C}$ utilizing the ${ }^{32} \mathrm{P}$-labelled HindIII/HindIII SARG cDNA fragment (854-1957) as a probe (Sambrook \& Russell 2001). Actin cDNA was utilized as a hybridization control. Blots were exposed to X-ray film with intensifying screens at $-80^{\circ} \mathrm{C}$.

\section{Analysis of tissue specific expression of mRNA by PCR}

Tissue specificity of SARG mRNA was assayed by semi-quantitative PCR on Human MTG Panel II cDNA (BD Biosciences Clontech), containing cDNAs from spleen, thymus, prostate, testis, ovary, small intestine, colon and peripheral blood lymphocytes, essentially according to the procedure described in the user manual. G3PDH primers from the cDNA kit were used as a control (30 amplification cycles). SARG primers utilized were 5'-AGTCTGAGGCAGCGACA ACT-3' (F-ex3) and 5'-TGTGGATATTCGTA GGGAGG-3' (R-ex4) (30 amplification cycles, primer annealing was at $55^{\circ} \mathrm{C}$ ).

\section{Immunocytochemistry}

LNCaP cells were seeded at a density of $3 \times 10^{5}$ cells per well on sterile micro-slides in four-well tissue culture plates (Heraeus Instruments, Hanau, Germany), cultured until 50\% confluence in RPMI 1640, supplemented with 5\% (v/v) FCS and antibiotics and subsequently transfected with $5 \mu \mathrm{g}$ pHisXpress-cSARG. After overnight incubation, cells were washed twice in PBS and fixed in acetone for $10 \mathrm{~min}$. Next, slides were rinsed twice in PBS, followed by overnight incubation in mouse anti-Xpress antibody solution (Invitrogen) diluted 1:500 in PBS at $4{ }^{\circ} \mathrm{C}$. Incubation was stopped by four PBS washes. Next, slides were incubated for $30 \mathrm{~min}$ at room temperature in goat anti-mouse peroxidase conjugate antibody (DAKO, Glostrup,
Denmark) solution (1:100 dilution in PBS). After four PBS washes, immunoreactivity was visualized by diaminobenzidine (DAB) staining. The reaction was stopped in water. Cells were counterstained with Mayers Hematoxylin.

\section{Isolation of genomic DNA fragments}

The SARG DD-PCR fragment was randomly ${ }^{32}$ P-labelled and utilized to screen a genomic human PAC library on gridded filters (GenomeSystems, St Louis, MO, USA) according to the manufacturer's protocol. DNA was isolated from positive PACs by standard procedure (Sambrook \& Russell 2001). For Southern blot analysis $10 \mu \mathrm{g}$ PAC90 L18 DNA was HindIII, PstI or EcoRI digested, electrophoresed on a $0 \cdot 8 \%$ TAE-agarose gel and subsequently transferred to a Hybond- $\mathrm{N}^{+}$ membrane. Filters were hybridized at high stringency with randomly ${ }^{32}$ P-labelled SARG probes under standard conditions (Sambrook \& Russell 2001). HindIII, PstI or EcoRI digested PAC DNA was shot-gun cloned in the corresponding sites of $\mathrm{pBSKS}^{+1-}$ (Stratagene). Clones were utilized for isolation of genomic fragments by screening with randomly ${ }^{32}$ P-labelled SARG cDNA fragments and for $S A R G$ gene walking with overlapping HindIII, PstI and EcoRI fragments. Hybridizing inserts were sequenced.

\section{Search for candidate androgen response elements}

The MatInspector professional program (www. genomatix.de/mat_fam) (Quandt et al. 1995) was utilized for detection of candidate AREs with queries for the inverted repeat 5'-RGWAGAN NNTGTTCT $-3^{\prime} \quad(\mathrm{R}=\mathrm{A} / \mathrm{G}, \mathrm{W}=\mathrm{G} / \mathrm{T})$ and the direct repeat 5'-TGTTGTNNNTGTTGT-3'. The threshold for candidate AREs was set at nine out of 12 matches. The MatInspector program searched both the sense and anti-sense strand. Identified sequences were further selected manually according to additional criteria. Candidate inverted repeat AREs should contain $G$ and $G$ at the double-underlined positions in the sequence above, and at least one of either single underlined G or G. Candidate direct repeat AREs should contain three out of four single-underlined $\mathrm{C}$ and $\mathrm{G}$ residues. 


\section{Cell culture, transfection and luciferase assay}

LNCaP and LNCaP-1F5 cells were cultured in RPMI 1640 supplemented with 5\% (v/v) FCS and antibiotics. Four hours prior to transfection the medium was substituted by Dulbecco's Modification of Eagle's Medium (DMEM) supplemented with 5\% (v/v) FCS-DCG. Transient transfections were performed following the calcium phosphate precipitation method (Sambrook \& Russell 2001) utilizing $1 \times 10^{6}$ cells per $25 \mathrm{~cm}^{2}$ flask and $5 \mu \mathrm{g}$ of one of the pLUC-constructs. After $4 \mathrm{~h}$ the medium was removed and cells were incubated for $90 \mathrm{~s}$ at room temperature in PBS containing 15\% (v/v) glycerol. Next, transfected cells were cultured in DMEM-FCS-DGG medium for $24 \mathrm{~h}$ in the absence or presence of $1 \mathrm{nM}$ R1881 or $10 \mathrm{nM}$ Dex. Transfected cells were washed in PBS, and subsequently incubated in $300 \mu \mathrm{l}$ lysis buffer (25 mM Tris-phosphate, $\mathrm{pH} 7 \cdot 8 ; 8 \mathrm{mM} \mathrm{MgCl}_{2}$; $1 \mathrm{mM}$ DTT; $1 \%$ (v/v) Triton X-100; 15\% (v/v) glycerol). Next, $100 \mu \mathrm{l} 0.25 \mathrm{mM}$ luciferin (Sigma, St Louis, MO, USA) and $0.25 \mathrm{mM}$ ATP in lysis buffer was added to $150 \mu$ lysate and luciferase activity was measured in a LUMAG $2500 \mathrm{M}$ Biocounter (LUMAC, Landgraaf, The Netherlands).

\section{Electrophoretic mobility shift assay}

AR DBD and GR DBD were produced in Escherichia coli and purified as described previously (De Vos et al. 1991). AR DBD and GR DBD were expressed from pRIT2 TAR and pRIT2 TrGRDBD respectively. The following oligonucleotide electrophoresis mobility shift assay (EMSA) probes were used: PSA ARE I: 5'-GATCGTTGGAGAA CAGCAAGTGCTAGCTG-3'; 3'-GAACGTCT TGTGGTTCACGATCGAGCTAG-5'; Probasin ARE II: 5'-TCGACTAGGTTCTTGGAGTACT TTG-3'; 3'-GATCGAAGAACGTCATGAAACA GCT-5'; ARE-SARG + 4•6: 5'-TGGACACTGTG CTAACTGTTCTCTG-3'; 3'-GTGACACGATT GACAAGAGACAGCT-5'; direct repeat (DR): 5'-TGGACACTGTTCTAACTGTTCTCTG-3'; 3'-GTGACAAGATTGACAAGAGACAGCT-5'; ARE-mSARG + 4·6: 5'-TGGACACTATGATAA CTATTATCTG-3' and 3'-GTGATACTATTGA TAATAGACAGCT-5'

Probes were filled in by standard M-MuLV-RT reaction in the presence of $\alpha-{ }^{32} \mathrm{P}-\mathrm{dATP}$ and subsequently purified on a non-denaturing polyacrylamide gel. For EMSA, 50 x $10^{3}$ c.p.m. probe was added to $20 \mu \mathrm{l}$ reaction mixture, containing $2 \mu \mathrm{g}$ poly dIdC, $2 \mu \mathrm{g}$ BSA, $10 \mu \mathrm{M} \mathrm{ZnCl}, 1 \mathrm{mM}$ DTT and $2 \mu \mathrm{l} 10 \mathrm{x}$ binding buffer $(100 \mathrm{mM}$ Hepes, $\mathrm{pH} 7 \cdot 6 ; 300 \mathrm{mM} \mathrm{KCl} ; 62 \cdot 5 \mathrm{mM} \mathrm{MgCl}{ }_{2} ; 4 \%$ (v/v) ficoll 400) and 5 pmol AR DBD or GR DBD. Incubation was for $30 \mathrm{~min}$ on ice. Samples were electrophoresed on a $4 \%(\mathrm{w} / \mathrm{v})$ polyacrylamide (19:1 mono/bis acryl ratio) gel in a $25 \mathrm{mM}$ Tris.HCl, $41.5 \mathrm{mM}$ boric acid, $0.5 \mathrm{mM}$ EDTA buffer for $2 \mathrm{~h}$ at $150 \mathrm{~V}$ at room temperature. Subsequently, gels were fixed, dried and exposed to $\mathrm{X}$-ray film.

\section{Chromatin immunoprecipitation (ChIP)}

ChIPs were done essentially according to the method described in the Acetyl-Histone H3 ChIP assay kit (Upstate Biotechnology, Chicago, Il, USA). In short, LNCaP cells were grown for at least 3 days in 5\% FGS-DGG supplemented RPMI 1640 medium. To half of the cultures R1881 was added to a final concentration of $10 \mathrm{nM}$. After $1 \mathrm{~h}$ cells were cross-linked with formaldehyde $(1 \%$ final concentration) at $22{ }^{\circ} \mathrm{C}$ for $10 \mathrm{~min}$. Cross-linking was stopped by addition of glycine to a final concentration of $125 \mathrm{mM}$. Next, cells were washed in ice-cold PBS and harvested in PBS supplemented with protease inhibitors (Roche Diagnostics). Cell pellets were resuspended in SDS lysis buffer and sonicated to shear the DNA. Sonicated samples were centrifuged, diluted in Chip Dilution Buffer (Upstate Biotechnology) and precleared by incubation with salmon sperm DNA/Protein A agarose slurry for $1 \mathrm{~h}$ at $4{ }^{\circ} \mathrm{C}$ with rotation. After centrifugation, immunoprecipitation of the supernatant was performed overnight at $4{ }^{\circ} \mathrm{C}$ with Acetyl-Histone H3 antibody. Next, salmon sperm DNA/Protein A agarose slurry was added, and the incubation was continued for another hour. Agarose beads were washed according to the procedure described by the manufacturer. Eluates were heated overnight at $65^{\circ} \mathrm{C}$ to reverse the cross-linking. DNA fragments were purified with a QIAquick Spin Kit (QIAGEN, Hilden, Germany). One $\mu$ from $50 \mu \mathrm{l}$ DNA solution was used in a standard PCR (35 amplification cycles). Primer sequences were $-8 \cdot 5 \mathrm{~F}$ : 5'-CAGGGACATGGAT GAAGCTG-3'; - 8.5R: 5'-GAACGGGTCATCT ACATTAG-3'; - 7·3F: 5'-GTAAGTCGAAGAC 
AGCTAGTC-3'; -7·3R: 5'-CTGAGATGCTGA GAGGCTGA-3'; +4·6F: 5'-CAAGTCTACAGT CTCGCATC-3' and +4.6R: 5'-CTGAAATCGC AGTTTAGCGA-3'. PGR fragments were separated over an agarose gel.

\section{Results}

\section{SARG mRNA expression in LNCaP-1F5 cells}

Utilizing DD-PCR technology we previously identified in LNCaP-1F5 prostate cancer cells, which express both $\mathrm{AR}$ and GR, a novel androgen-specific regulated gene, denoted $21 \cdot 1$ in the initial study and $S A R G$ in the present study (Cleutjens et al. 1997). SARG mRNA expression was found to be up-regulated by the synthetic androgen R1881, but not by the synthetic glucocorticoid Dex. Utilizing the DD-PCR fragment as hybridization probe, a $5.5 \mathrm{~kb}$ transcript was identified in R1881-incubated LNCaP-1F5 cells.

For further characterization of SARG we first isolated full-length SARG mRNA. Overlapping SARG cDNA fragments were obtained by repeated screening of a human prostate cDNA library. In the first screen, the DD-PCR fragment was utilized as a hybridization probe (Fig. la). The longest cDNA, containing a polyadenylation signal and a polyA tail, was $3.6 \mathrm{kbp}$. Screening of the cDNA library with a $5^{\prime}$ fragment of this cDNA as a probe resulted in the detection of an overlapping $2.7 \mathrm{kbp}$ cDNA with a second polyadenylation signal and a polyA tail. This cDNA fragment extended the cDNA sequence to approximately $4.9 \mathrm{kbp}$. Further, 5' SARG cDNA sequence was obtained by RACE-PGR, utilizing a primer in the $2 \cdot 7 \mathrm{kbp}$ cDNA. Two related $5^{\prime} \mathrm{cDNA}$ fragments of $665 \mathrm{bp}$ and $537 \mathrm{bp}$, were found. The shorter fragment (RACE2) lacked nucleotides 42-169 of the longer fragment (RACE1) (Fig. 1a). The longest SARG cDNA sequence of $5487 \mathrm{bp}$ was deposited in GenBank under Accession Number AY352640.

A BLAST search of the EST database (www.ncbi.nlm.nih.gov/) identified two EST clusters overlapping the SARG cDNA sequence. The first group represented the $3^{\prime}$ parts of the $5.5 \mathrm{~kb}$ and $3.3 \mathrm{~kb}$ transcripts, as detected in the cDNA library (Unigene cluster Hs.32417), the second cluster represented a $2.3 \mathrm{~kb}$ transcript, which contained SARG 5' cDNA sequences and a third polyadenylation sequence and polyA tail (Unigene cluster Hs.223394). We confirmed the presence of three polyadenylation signals in the $5.5 \mathrm{kbp}$ SARG cDNA sequence (Fig. 1a). A $1 \cdot 1 \mathrm{kbp}$ SARG cDNA fragment (nucleotides 854 to 1957) hybridized with all three predicted SARG mRNAs in a Northern blot of LNCaP-1F5 RNA (Fig. 1b). The $3 \cdot 3 \mathrm{~kb}$ transcript showed the highest expression. All SARG transcripts were up-regulated by R1881 but their expression could not be induced by Dex. Semi-quantitative RT-PGR indicated high SARG mRNA expression in prostate tissue (Fig.lc, lane 3) as compared with spleen, thymus, testis, ovary, small intestine, colon and lymphocytes.

\section{SARG protein}

The SARG open reading frame $(\mathrm{ORF})$ encodes a 601 amino acid protein (Fig. 2a). This ORF is identical to that of the hypothetical protein MGC2742 (Genbank). Because Unigene cluster Hs.23417 encompasses the $3^{\prime}$ part of the two longest SARG transcripts, a predicted protein from this EST cluster (MGC4309) is unlikely.

To determine its cellular localization, SARG protein was Xpress-tagged and transiently expressed in LNGaP cells. Immunocytochemical staining with anti-Xpress antibody showed that SARG protein was exclusively present in the cytoplasm (Fig. 2b).

\section{SARG gene structure and splice variants}

The complete $S A R G$ gene was isolated in one PAC (90 L18) by screening of a human genomic PAC library with the SARG DD-PCR fragment (see Fig. la) as probe. To characterize $S A R G$, subcloned overlapping HindIII, PstI and EcoRI fragments of PAC 90 L18 were hybridized with appropriate cDNA fragments. Comparison with the cDNA sequence revealed that $S A R G$ was composed of four exons, and spanned 14.5 kbp (Fig 3a). The two cDNA fragments obtained by RACE-PCR represented two forms of exon 1, the short exon 1A, and the extended exon 1AB. All splice junctions were consistent with the GT/AG rule (Fig. 3b). The SARG ORF started in exon 2 and ended in the large exon 4 (Fig. 3a). SARG is part of BAC RP11-564A8 (Genbank Accession Number AC098935.2). The transcription start site is at 
(a)

\section{SARG CDNA}
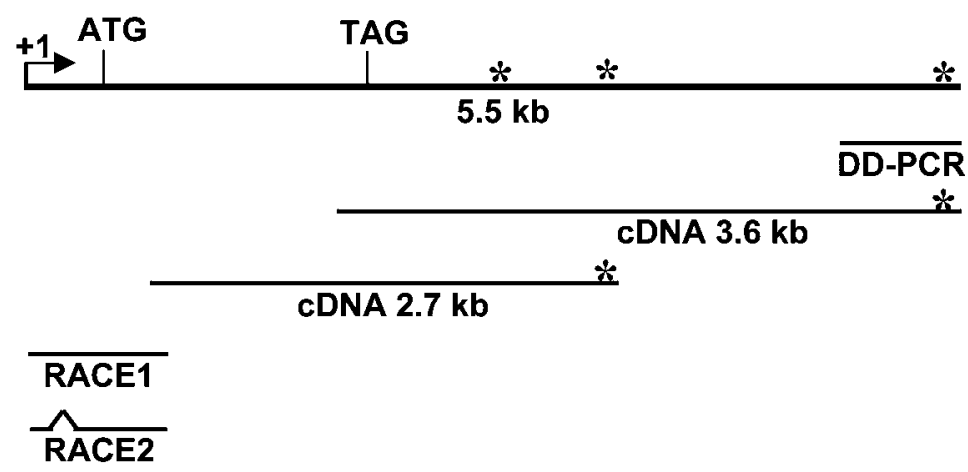

(b)

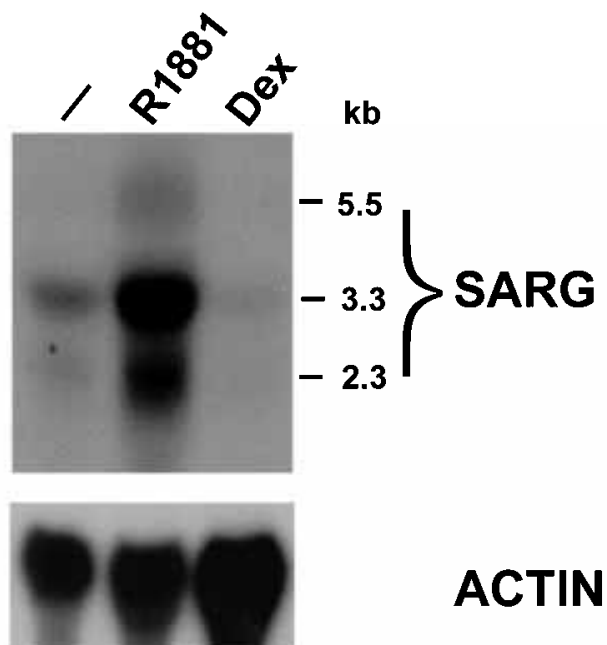

(c)

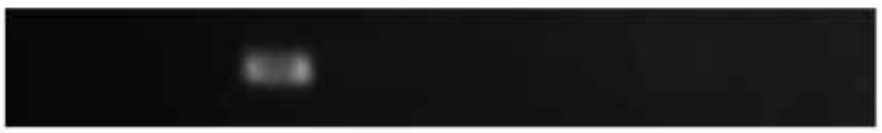

SARG

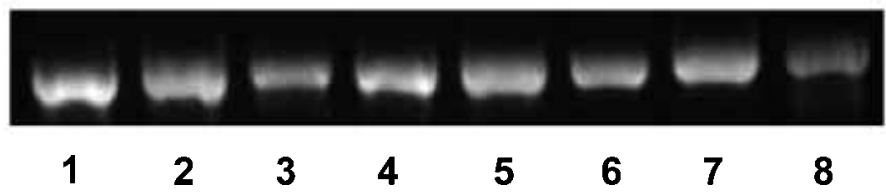

G3PDH

Figure 1 SARG cDNA, and androgen-regulated and prostate specific SARG mRNA expression. (a) Schematic overview of the isolation of the complete SARG cDNA. The start and stop codons are indicated. An asterisk indicates a polyadenylation signal. DD-PCR indicates the original differential display fragment (Cleutjens et al. 1997). RACE1 and RACE2 are two related $5^{\prime}$ ends of SARG CDNA. (b) Northern blot of SARG mRNA expression in LNCaP-1F5 cells incubated for $24 \mathrm{~h}$ without hormone $(-)$, with $1 \mathrm{nM}$ R1881 or $10 \mathrm{nM}$ Dex. Transcript sizes are indicated. Actin was utilized as a loading control. (c) RT-PCR analysis of SARG mRNA expression in (1) spleen,

(2) thymus, (3) prostate, (4) testis, (5) ovary, (6) small intestine, (7) colon and

(8) lymphocytes. cDNAs were normalized for G3PDH expression as loading control. 
(a)

251
251
1

(b)
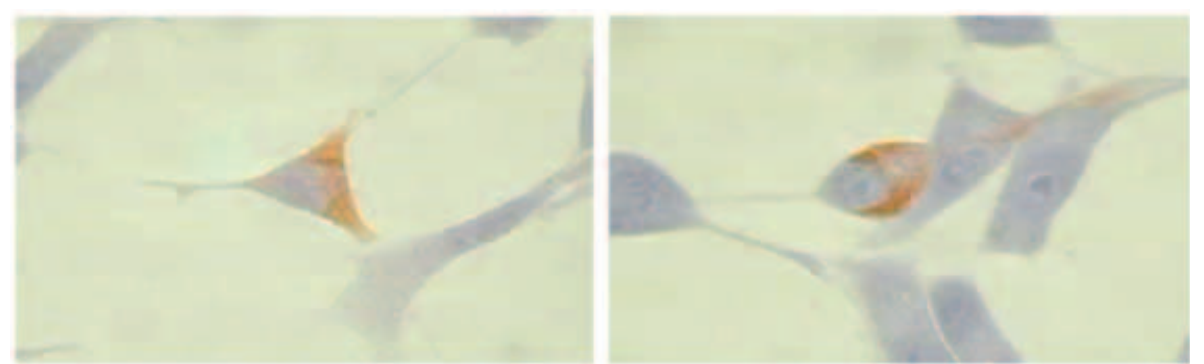

Figure 2 The SARG open reading frame and the cellular localization of the SARG protein. (a) The SARG ORF encodes a protein of 601 amino acids. Methionine 247 (in bold) is the first amino acid residue of the shorter SARG protein translated from mRNA lacking exon $1 \mathrm{~B}$ and/or exon 2 sequences. (b) The SARG protein is located in the cytoplasm. LNCaP cells were transfected with pcHisXpress-cSARG encoding Xpress-tagged SARG protein. Xpress-SARG was visualized by immunostaining with anti-Xpress antibody. 
(a)

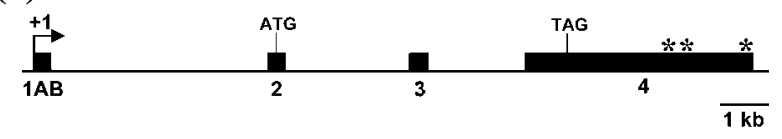

(b)

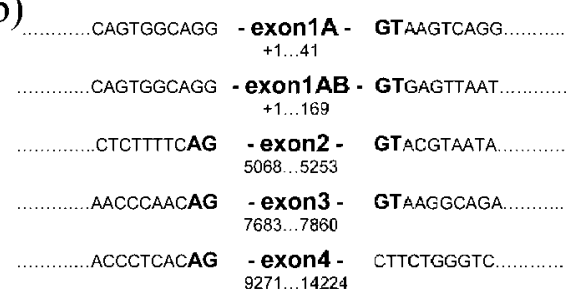

(c)

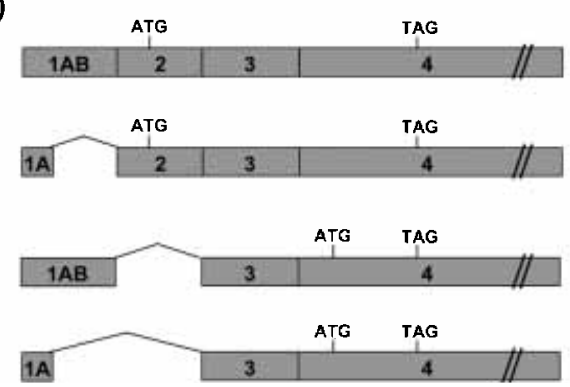

Figure $3 S A R G$ gene structure and splice variants. (a) Schematic presentation of the SARG gene. The ATG start codon in exon 2 and the TAG stop codon in exon 4 are indicated. The three asterisks indicate polyadenylation signals. (b) Splice donor and acceptor sites at the exon/intron boundaries in the SARG gene. Numbering is according to the genomic SARG sequence. (c) Four different splice variants of the SARG gene. Start and stop codons are indicated.

position 184776 in this clone. SARG maps at chromosome band 1q32.2.

RAGE-PGR and RT-PGR revealed four different SARG splice variants (Fig. 3c). The largest variant contained all exons, smaller variants lacked either part $\mathrm{B}$ of exon $1 \mathrm{AB}$, exon 2 or both. The splice variants lacking exon 2, which formed a minority, are predicted to encode a protein of 355 amino acids, starting at methionine 247 (Fig. 2a). The corresponding ATG codon is in exon 4, in frame with the long SARG ORF (Fig 3c).

\section{Functional and bioinformatics-based selection of candidate androgen response elements}

To establish androgen response of $S A R G$, the promoter fragments SARG-L $(-3012$ to +168$)$ and SARG-S ( -55 to +168$)$ were inserted in front of the luciferase reporter gene in the constructs pSARG-L-LUC and pSARG-S-LUG respectively. Transient transfection of these constructs to LNCaP cells showed in both cases a very weak androgen response, indicative of the absence of strong AR binding sites (see Fig. 4d). This prompted us to screen for candidate AREs in a region of approximately $18 \mathrm{kbp}$, from $9 \mathrm{kbp}$ upstream to $9 \mathrm{kbp}$ downstream of the transcription start site using a bioinformatics-based approach. This sequence is present in BACs AC098935.2 and AC023534. The MatInspector program was applied to search both DNA strands for sequences homologous to the direct repeat 5'-TGTTGT nnnTGTTCT-3' or to the inverted repeat consensus $\overline{\mathrm{ARE}}$ sequence 5'-A/GGA/TACAnnnTGT TCT -3' (see Materials and methods). $\overline{\text { We selected }}$ sequences that showed at least nine out of 12 matches in the two half sites. Out of the sequences obtained, candidate AREs were further selected manually, based on the criteria of presence of at least three out of four underlined $\mathrm{G}$ or $\mathrm{G}$ residues in the direct repeat or presence of the doubleunderlined $\mathrm{G}$ and $\mathrm{G}$ residue and at least one of the two single-underlined $\mathrm{C}$ and $\mathrm{G}$ residues in the inverted repeat. Utilizing this approach, we identified 34 candidate AREs in the $18 \mathrm{kbp}$ region, 12 inverted repeats and 22 direct repeats. None of these was completely identical to the consensus inverted repeat. One was a perfect direct repeat and two sequences deviated at one position from a perfect direct repeat. Four sequences matched the inverted or direct repeat at ten out of 12 positions. Several candidate AREs clustered in the genome. At approximately $-8.5 \mathrm{kbp}$ a cluster of four candidate AREs was present, including the imperfect direct repeat 5'-TGAACAatgAGA ACA-3' (11/12 matches). At $+4 \cdot 6 \mathrm{kbp}$ a cluster of five candidate AREs was detected, including the imperfect direct repeat 5'-TGTGCTaacTGT TCT-3' (11/12 matches). The latter cluster is located in $S A R G$ intron 1. The perfect direct repeat 5'-TGTTCTcctTGTTCT-3' mapped at $-7 \cdot 3$ $\mathrm{kbp}$, one ARE-like sequence was close to this repeat (Fig. 4a,b).

Next, it was investigated whether three genomic fragments containing the indicated direct repeats and flanking candidate AREs could function as enhancer regions. Genomic fragments with a size of approximately $500 \mathrm{bp}, \mathrm{SARG}-8 \cdot 5$, 
(a)

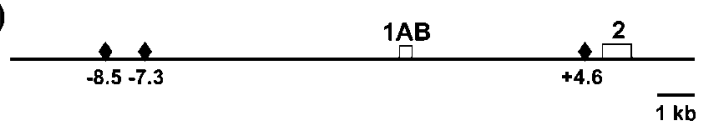

(b)

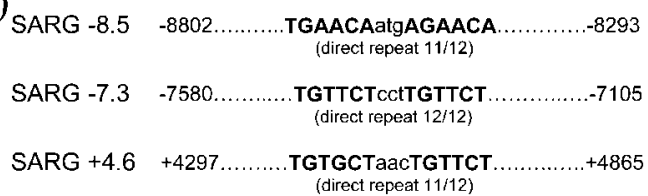

(c)

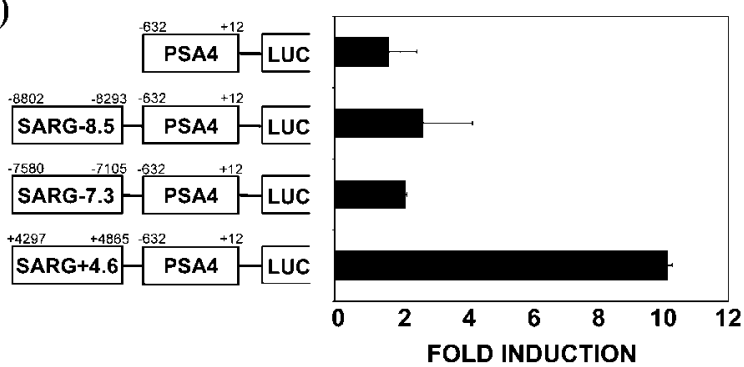

(d)

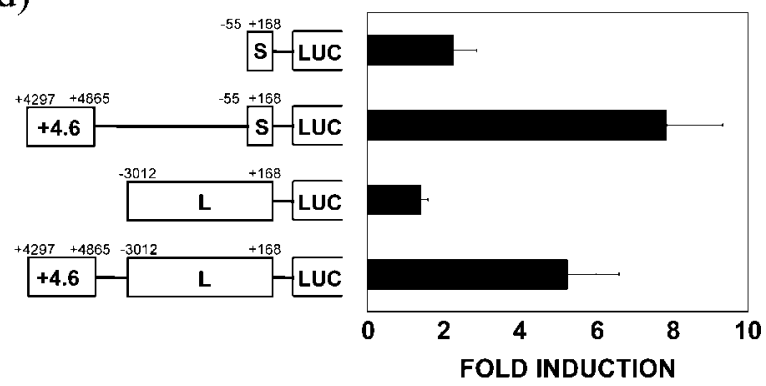

Figure 4 Three direct repeat candidate androgen response elements in the SARG gene. (a) Positions (kbp) of the three direct repeat candidate AREs ( $\downarrow)$ in the $S A R G$ gene. (b) Sequences and location of the three direct repeat candidate AREs in the SARG gene. Numbering is according to the genomic SARG sequence. Matching to the direct repeat $5^{\prime}$-TGTTCTnnnTGTTCT-3' is indicated below the sequences. (c) Androgen-induced activity of the SARG fragments, containing a direct repeat candidate ARE, coupled to the PSA4 promoter. LNCaP cells were transiently transfected with pPSA-4-LUC, pSARG-8.5-PSA-LUC, pSARG-7.3-PSALUC or pSARG+4-6-PSA-LUC. Luciferase activity was measured after $24 \mathrm{~h}$ incubation with or without $1 \mathrm{nM}$ R1881. (d) Androgen-induced activity of SARG $+4 \cdot 6$ coupled to SARG-S and SARG-L respectively. LNCaP cells were transfected with pSARG-S-LUC, pSARG+4.6SARG-S-LUC, pSARG-L-LUC or pSARG + 4.6-SARG-LLUC. After $24 \mathrm{~h}$ incubation with or without $1 \mathrm{nM}$ R1881 luciferase activity was measured. Value +/- S.E.M. in (c) and (d) are from two experiments carried out in duplicate. Fold induction is the ratio of luciferase activity measured in the presence and absence of R1881.
SARG $-7 \cdot 3$ and $\mathrm{SARG}+4 \cdot 6$, were coupled to PSA4-LUC, containing the 600 bp promoter of the PSA gene. This promoter was weakly responsive to androgens but combination with an upstream PSA enhancer fragment resulted in a strong androgeninducible promoter (Cleutjens et al. 1997). In transfected LNCaP cells, SARG -8.5 and SARG $-7 \cdot 3$ had no significant effect on the weak R1881 induction of the PSA4 promoter. In contrast, SARG $+4 \cdot 6$ clearly increased R1881 induced PSA4 activity (Fig. 4c). Next, SARG $+4 \cdot 6$ was linked to SARG-S $(-55$ to +168$)$ and SARG-L $(-3012$ to +168 ), which both showed, as mentioned above, a very low androgen induction. Similar to the PSA promoter experiment, linkage of $\mathrm{SARG}+4 \cdot 6$ to both SARG-L and SARG-S showed androgen response in transfected LNCaP cells (Fig. 4d).

\section{SARG intron 1 contains a functional direct repeat androgen response element}

To determine whether the imperfect direct repeat 5'-TGTGCTaacTGTTCT-3' in SARG +4.6 was responsible for androgen induction it was mutated to $5^{\prime}$-TATGATaacTATTAT-3'. The mutated fragment was coupled to SARG-S and tested in LNCaP cells for its response to R1881. As shown in Fig. $5 \mathrm{a}$, the androgen induction of SARG $+4 \cdot 6$ was completely abolished by the mutations.

Next, the direct repeat 5'-TGTGGTaacTGT TCT- $3^{\prime}$ in SARG $+4 \cdot 6$, designated ARE-SARG $+4 \cdot 6$, was tested in an EMSA for its ability to bind to AR DBD (Fig. 5b). Control AREs were PSA ARE I (5'-AGAACAgcaAGTGCT-3'), which has been shown to bind strongly to the AR DBD, and rat probasin ARE II (5'-GGTTCTtggAGT ACT- $3^{\prime}$ ), which is considered as a direct repeat, strongly interacting with AR DBD (Riegman et al. 1991, Rennie et al. 1993, Claessens et al. 1996, Cleutjens et al. 1996). ARE-SARG $+4 \cdot 6$ bound to AR DBD, albeit more weakly than the PSA and probasin AREs. The change of ARE-SARG $+4 \cdot 6$ into the perfect DR 5'-TGTTCTaacTGTTCT-3' did not affect its capacity to bind AR DBD. AR DBD was unable to bind inactive mutant ARE-mSARG + 4·6 (5'-TATGATaacTATTAT-3').

\section{Characterization of enhancer SARG +4.6}

To further decipher the role of the $569 \mathrm{bp}$ enhancer SARG + 4·6- $(+4297 /+4865)$ in androgen 
(a)

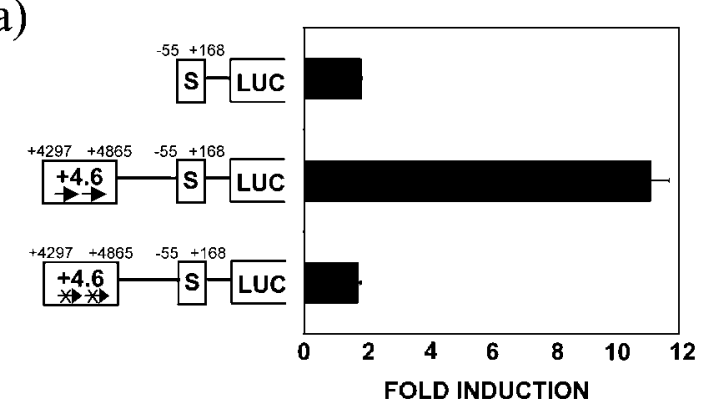

(b)

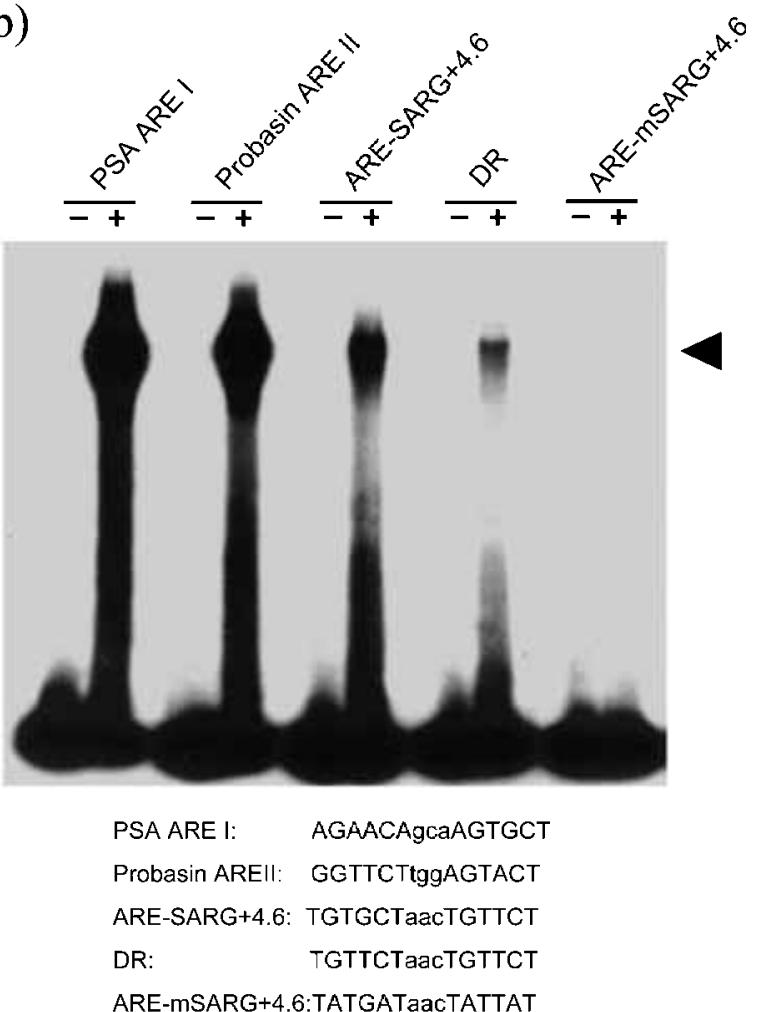

Figure 5 The direct repeat in $S A R G+4.6$ is a functional androgen response element. (a) Effect of mutation of ARE-SARG +4.6 on the transcriptional activity of $S A R G+4 \cdot 6$. $L N C a P$ cells were transfected with pSARG-S-LUC, pSARG+4.6-SARG-S-LUC or pSARG+4.6 m-SARG-S-LUC and incubated for $24 \mathrm{~h}$ with or without $1 \mathrm{nM} \mathrm{R1881}$. Transcriptional activity was measured in a luciferase assay. Values +/- S.E.M. are from two experiments carried out in duplicate. Fold induction is the ratio of luciferase activity measured in the presence and absence of R1881. (b) EMSA of indicated AREs and AR DBD. ARE sequences are shown below the Figure. The arrowhead indicates the position of the AR DBD-ARE complex.

regulation, two deletion constructs of SARG $+4 \cdot 6$ S-LUG were generated. Construct SARG +4.6(+4447/4659) lacked all four candidate weak ARE sequences present in the $\mathrm{SARG}+4 \cdot 6$ enhancer, but contained the imperfect direct repeat ARE $(\mathrm{ARE}-\mathrm{SARG}+4 \cdot 6)$. The $112 \mathrm{bp}$ enhancer fragment SARG + 4·6-(+4548/4659) lacked even more upstream sequences, but also still contained ARE$\mathrm{SARG}+4 \cdot 6$. In transfection experiments the shortened enhancer SARG+4·6-(4447/4659) was less active than the $569 \mathrm{bp}$ fragment, suggesting that clustering of ARE-SARG $+4 \cdot 6$ with weak ARE-like sequences is important for full enhancer activity (Fig. 6a). Interestingly, further shortening of the enhancer completely abolished its activity, although ARE-SARG $+4 \cdot 6$ was still present. However, in the deleted region we could not detect an obvious ARE-like sequence.

We carried out ChIP assays in order to investigate the in vivo function of enhancer SARG $+4 \cdot 6$. Utilizing an antibody directed against acetylated histone $\mathrm{H} 3$, we observed a difference in $\mathrm{H} 3$ acetylation over SARG $+4 \cdot 6$ between $\mathrm{LNCaP}$ cells grown in the presence and in the absence of $\mathrm{R} 1881$, showing a difference in chromatin structure on this part of the gene (Fig. 6b). The higher signal with AcH3 antibody in the presence of R1881 indicated an active structure of the enhancer region. Such a difference was not detected for the genomic fragments SARG -8.5 and $\mathrm{SARG}-7 \cdot 3$. These findings were in accordance with the transient transfection studies, as shown in Fig. 4c. Unfortunately, ChIP assays with a large series of different antibodies against the AR were not successful, probably due to the low affinity of AR for ARE-SARG $+4 \cdot 6$.

\section{ARE-SARG +4.6 is androgen receptor specific}

To address the question of whether ARE$\mathrm{SARG}+4 \cdot 6$ is involved in androgen specificity, SARG $+4 \cdot 6$ coupled to both SARG-S-LUG and PSA4-LUG was tested for activation by Dex. The constructs were transfected to LNCaP-1F5 cells cultured in the presence of $1 \mathrm{nM} \mathrm{R} 1881$ or $10 \mathrm{nM}$ Dex or in the absence of hormone (Figure 7a,b). SARG $+4 \cdot 6$ did not significantly stimulate Dex induced activity of SARG-S and PSA4. In contrast, R1881 induced activity of these two promoters was clearly increased by SARG $+4 \cdot 6$.

ARE-SARG $+4 \cdot 6$ was also tested in an EMSA for its ability to bind to GR DBD (Fig. 7c). Control PSA ARE I did bind to GR DBD, but rat probasin ARE II did not. Importantly, ARE-SARG $+4 \cdot 6$ 
(a)

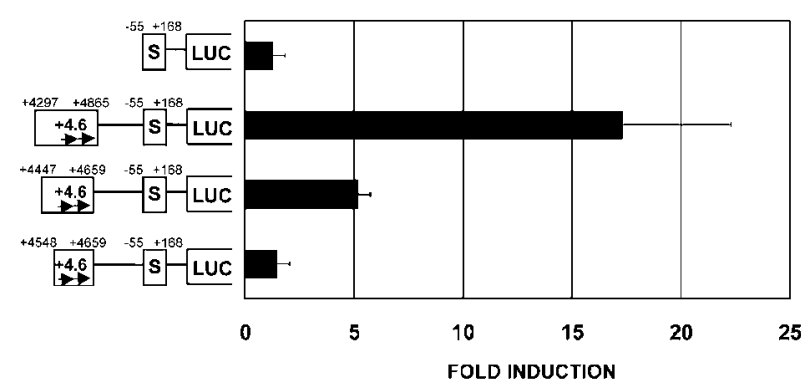

(b)

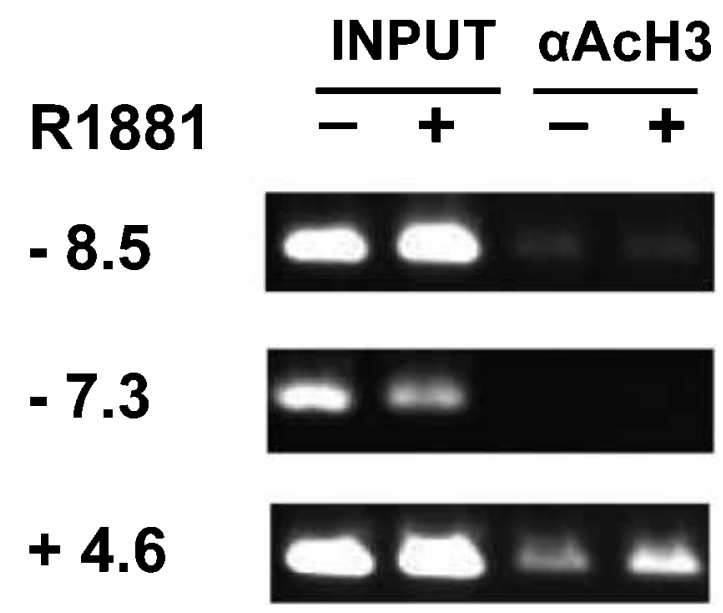

Figure 6 Characterization of enhancer SARG $+4 \cdot 6$.

(a) Deletion mapping of enhancer SARG $+4 \cdot 6$ in transiently transfected LNCaP cells. See legend to Fig. $5 \mathrm{a}$ and Materials and methods for experimental details. (b) ChIP assay of the candidate $-8.5 \mathrm{~kb}$, $-7.3 \mathrm{~kb}$ and $+4.6 \mathrm{~kb}$ enhancer regions of $S A R G$ in the presence and absence of R1881. Acetyl-Histone H3 antibody was used for immunoprecipitation.

Experimental details are described in Materials and methods. Input, DNA prior to immunoprecipitation.

was also not able to bind to GR DBD, which correlated with the R1881 specificity of SARG $+4 \cdot 6$ in the transfection assay.

\section{Discussion}

The androgen-specific regulated $S A R G$ gene was identified in the LNCaP-1F5 subline that expresses endogenous $\mathrm{AR}$ and GR from a stable-integrated (a)

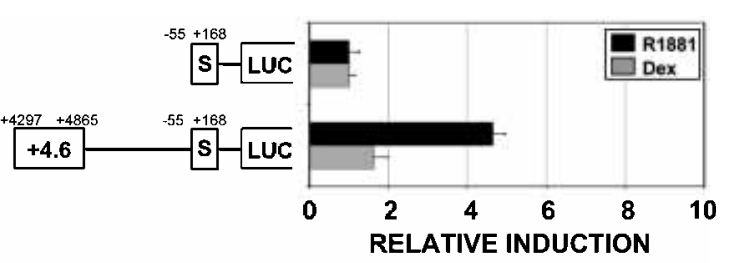

(b)

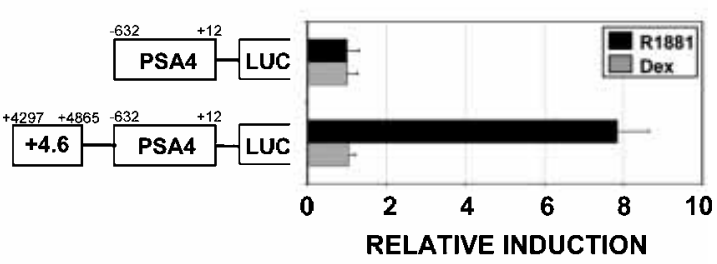

(c)

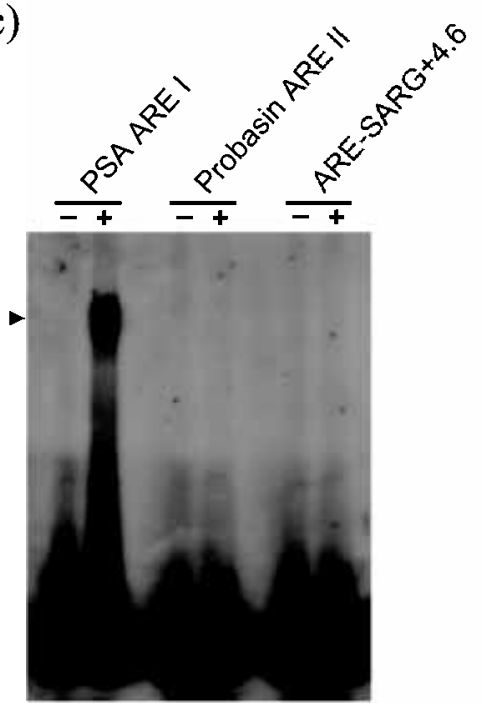

Figure 7 ARE-SARG+4.6 is androgen receptor specific. LNCaP-1F5 cells were transfected with

(a) pSARG-S-LUC and PSARG+4.6-SARG-S-LUC and (b) pPSA4-LUC and pSARG+4-6-PSA-LUC. Luciferase activity was measured after $24 \mathrm{~h}$ incubation with $1 \mathrm{nM}$ R1881 or $10 \mathrm{nM}$ Dex or without hormone. R1881 and Dex induced activities of (a) SARG-S-LUC and (b) PSA4-LUC were set at 1. Relative inductions $+/$ - S.E.M. are from two experiments carried out in duplicate. (c) EMSA of AREs with GR DBD. Sequences of the DNA fragments analysed are shown in Figure 5(b). GR DBD-ARE complexes are indicated by the arrowhead.

cDNA expression vector (Cleutjens et al. 1997). We showed that SARG mRNA expression could be up-regulated by androgens, but not by glucocorticoids. SARG is a four-T exon gene of $14.5 \mathrm{kbp}$, mapping to chromosome band 1q32.2. Exon 1 can 
appear in a short or long form, $1 \mathrm{~A}$ and $1 \mathrm{AB}$ respectively. The $2 \cdot 3,3.3$ and $5.5 \mathrm{~kb}$ transcripts result from alternative polyadenylation. Splice variants might lack either exon 2, part B of exon 1, or both. The predicted genes $M G C 2742$ and $M G C 4309$ are both part of SARG. SARG is preferentially expressed in the prostate (Fig. 1C). Our findings are substantiated by data in the expression profile database GeneNote (http:// bioinformatics/weizmann.ac.il/cards/). In this database high $S A R G$ expression was only documented for prostate and lung.

The SARG ORF encodes a protein of 601 amino acids; splice variants lacking exon 2 are expected to code for a carboxyl-terminal fragment of 355 amino acids of the full-length protein. Transient transfection experiments showed that the SARG protein is located in the cytoplasm. No homology to other proteins was found. Unfortunately, the amino acid composition of SARG does not indicate motifs that could predict its function. The SARG mouse ortholog has 605 amino acids, with a homology to human SARG of $65 \%$. Highest homology is in the amino-terminal and carboxyl-terminal regions of the proteins (data not shown).

To explain androgen specificity of SARG expression we first studied a $3 \mathrm{kbp}$ promoter region in transfection assays. Because these experiments were unsuccessful, we decided to carry out an in silico search for candidate AR binding sites in thel8 kbp flanking the $S A R G$ transcription start site. The search criteria were based on three or less deviations from a perfect direct repeat or the consensus high affinity ARE inverted repeat. We identified 34 candidate AREs. Functional studies, based on clustering of candidate AREs, indicated that an imperfect direct repeat in intron 1, 5'-TGT GCTaacTGTTCT-3' (ARE-SARG+4·6) was active and AR-specific. Importantly, ARE-SARG $+4 \cdot 6$ cooperated with surrounding sequences in a 569 bp enhancer region for full activity. Part of the cooperating sequences might be weak AR binding sites. However, others might be binding sites for prostate specific and more common transcription factors. The properties of these factors remain to be identified.

Mutation of ARE-SARG $+4 \cdot 6$ to a perfect repeat did not affect AR DBD binding. However, SARG $-7 \cdot 3$, which contains a perfect direct repeat, did not show any detectable androgen- induction in transfections. Also, linkage of SARG $-7 \cdot 3$ to SARG + 4.6-SARG-S did not increase the activity of SARG $+4 \cdot 6-\mathrm{SARG}-\mathrm{S}$ in transfections (data not shown). In contrast to ARE-SARG + 4.6, ARE-SARG - 7.3 might lack favourable modulating flanking sequences (Nelson et al. 1999) or binding sites for other transcription factors in its close vicinity. This might also be true for inactivity of ARE-SARG $-8 \cdot 5$.

The present study shows that a bioinformaticsbased search for AR binding sites followed by selected functional studies can successfully identify active regulatory elements. However, it shows also the limitations of such an approach due to the complexity of the regulation mechanism of gene expression. The functional studies were limited to the two largest clusters of candidate AREs, and to a small cluster containing a perfect direct repeat in an $18 \mathrm{kbp}$ region. Without clustering as a selection criterion, the bioinformatics approach would not have been selective because of the high density of candidate AREs (one per $500 \mathrm{bp}$ ). We realize that functional AREs in enhancers and promoters might also cluster with binding sites for other transcription factors. Moreover, although less likely, it cannot be completely excluded that some candidate ARE sequences did not pass the selection criteria. One such ARE should be in SARG-S ( -55 to +168$)$, which is weakly androgen inducible. A candidate is the sequence 5'-GGGCGAggcAGCACA-3' (+5 to +17 ) in exon 1 , which deviates at four positions from a perfect direct repeat.

A complicating factor in direct repeat ARE search is the lack of a consensus sequence for high-affinity, high-specificity AR binding due to the limited number of this type of AREs identified so far. Rat probasin ARE II (5'-GGTTCTtggAGT ACT-3'), which deviates from a perfect direct repeat at three positions, seems at present the specific ARE with highest AR affinity (Rennie et al. 1993, Kasper et al. 1994, Claessens et al. 1996, Kasper et al. 1999, Claessens et al. 2001). However, a search of the $18 \mathrm{kbp} S A R G$ sequence did not detect candidate AREs closely resembling this sequence (data not shown). Our data provide the first evidence that an almost perfect direct 5'-TGT TCT-3' repeat, as present in $\mathrm{SARG}+4 \cdot 6$, can function as an AR-specific element in a natural enhancer. Other direct repeat-like functional AREs with variable $A R$ specificity have been found in the 
$S C$ (secretory component) gene, the mouse Slp (sex limited protein) gene and the PEM (placenta and embryo) homeobox gene, which all deviate at least at three positions from a perfect direct repeat (Verrijdt et al. 1999, Verrijdt et al. 2000, Barbulescu et al. 2001).

Comparison of functional AREs of a large series of preferentially androgen regulated genes should reveal the sequence of a consensus high-affinity, high-specificity AR binding site in a natural context. Such genes might be identified by expression profiling of the AR and GR positive LNCaP-1F5 cell line followed by an unbiased functional study of a large series of overlapping fragments flanking the transcription start sites of these genes. This should also give a better insight in selection criteria for a bioinformatics-based search for functional AR binding sites in novel genes. Such an approach might also include comparison with data from other species.

It may be possible that the composition of an ARE can influence receptor activity by transduction of a particular conformation via the DNA-bound DBD to other AR domains. Recent evidence indicates that binding to different AREs indeed induces different conformational changes (Geserick et al. 2003). A different DBD conformation might directly or indirectly affect the association with coactivators, as shown for ER (Wood et al. 2001, Hall et al. 2002). In addition, it remains to be elucidated whether the ARE sequence is the major molecular determinant of AR specificity, or whether AR protein-protein interactions, including interactions with other specific transcription factors can contribute significantly to receptor specificity (Karvonen et al. 1997, Scheller et al. 1998).

\section{Acknowledgement}

This work was supported in part by a grant from the Dutch Cancer Society KWF. We thank Karin Hermans for technical support and art work.

\section{References}

Aranda A \& Pascual A 2001 Nuclear hormone receptors and gene expression. Physiological Revieres 81 1269-1304.

Barbulescu K, Geserick C, Schuttke I, Schleuning WD \& Haendler B 2001 New androgen response elements in the murine pem promoter mediate selective transactivation. Molecular Endocrinology $151803-1816$
Berns EM, de Boer W \& Mulder E 1986 Androgen-dependent growth regulation of and release of specific protein $(\mathrm{s})$ by the androgen receptor containing human prostate tumor cell line LNCaP. Prostate 9 247-259.

Claessens F, Dirckx L, Delaey B, Decourt JL, Hemschoote K, Peeters B \& Rombauts W 1989 The androgen-dependent rat prostatic binding protein: comparison of the sequences in the $5^{\prime}$ part and upstream region of the $\mathrm{C} 1$ and $\mathrm{C} 2$ genes and analysis of their transcripts. Fournal of Molecular Endocrinology $\mathbf{3}$ 93-103.

Claessens F, Alen P, Devos A, Peeters B, Verhoeven G \& Rombauts W 1996 The androgen-specific probasin response element 2 interacts differentially with androgen and glucocorticoid receptors. Fournal of Biological Chemistry 271 19013-19016.

Claessens F, Verrijdt G, Schoenmakers E, Haelens A, Peeters B, Verhoeven G \& Rombauts W 2001 Selective DNA binding by the androgen receptor as a mechanism for hormone-specific gene regulation. Fournal of Steroid Biochemistry and Molecular Biology 76 23-30.

Cleutjens CB, Steketee K, van Eekelen CG, van der Korput JA, Brinkmann AO \& Trapman J 1997 Both androgen receptor and glucocorticoid receptor are able to induce prostate-specific antigen expression, but differ in their growth-stimulating properties of LNCaP cells. Endocrinology 138 5293-5300.

Cleutjens KB, van Eekelen CG, van der Korput HA, Brinkmann AO \& Trapman J 1996 Two androgen response regions cooperate in steroid hormone regulated activity of the prostate-specific antigen promoter. Fournal of Biological Chemistry $2716379-6388$

De Vos P, Claessens F, Winderickx J, Van Dijck P, Celis L, Peeters B, Rombauts W, Heyns W \& Verhoeven G 1991 Interaction of androgen response elements with the DNA-binding domain of the rat androgen receptor expressed in Escherichia coli. Fournal of Biological Chemistry 266 3439-3443.

De Vos P, Claessens F, Celis L, Peeters B, Rombauts W, Heyns W \& Verhoeven G 1994 Nuclear extracts enhance the interaction of fusion proteins containing the DNA-binding domain of the androgen and glucocorticoid receptor with androgen and glucocorticoid response elements. Foumal of Steroid Biochemistry and Molecular Biology 48 317-323.

Devos A, Claessens F, Alen P, Winderickx J, Heyns W, Rombauts W \& Peeters B 1997 Identification of a functional androgen-response element in the exon 1-coding sequence of the cystatin-related protein gene crp2. Molecular Endocrinology 11 $1033-1043$

Geserick G, Meyer HA, Barbulescu K \& Haendler B 2003 Differential modulation of androgen receptor action by deoxyribonucleic acid response elements. Molecular Endocrinology 17 1738-1750.

Glass CK \& Rosenfeld MG 2000 The coregulator exchange in transcriptional functions of nuclear receptors. Genes and Development $14121-141$.

Haelens A, Verrijdt G, Callewaert L, Christiaens V, Schauwaers K, Peeters B, Rombauts W \& Claessens F 2003 DNA recognition by the androgen receptor: evidence for an alternative DNA-dependent dimerization, and an active role of sequences flanking the response element on transactivation. Biochemical Journal 369 141-151.

Hall JM, McDonnell DP \& Korach KS 2002 Allosteric regulation of estrogen receptor structure, function, and coactivator recruitment by different estrogen response elements. Molecular Endocrinology 16 469-486.

Ham J, Thomson A, Needham M, Webb P \& Parker M 1988 Characterization of response elements for androgens, glucocorticoids and progestins in mouse mammary tumour virus. Nucleic Acids Research 16 5263-5276.

Heinlein CA \& Chang C 2002 Androgen receptor (AR) coregulators: an overview. Endocrine Reviews 23 175-200. 
Horoszewicz JS, Leong SS, Kawinski E, Karr JP, Rosenthal H, Chu TM, Mirand EA \& Murphy GP 1983 LNCaP model of human prostatic carcinoma. Cancer Research 43 1809-1818.

Karvonen U, Kallio PJ, Janne OA \& Palvimo JJ 1997 Interaction of androgen receptors with androgen response element in intact cells. Roles of amino- and carboxyl-terminal regions and the ligand. Fournal of Biological Chemistry 272 15973-15979.

Kasper S, Rennie PS, Bruchovsky N, Sheppard PC, Cheng H, Lin L, Shiu RP, Snoek R \& Matusik RJ 1994 Cooperative binding of androgen receptors to two DNA sequences is required for androgen induction of the probasin gene. Fournal of Biological Chemistry 269 31763-31769.

Kasper S, Rennie PS, Bruchovsky N, Lin L, Cheng H, Snoek R, Dahlman-Wright K, Gustafsson JA, Shiu RP, Sheppard PC et al. 1999 Selective activation of the probasin androgen-responsive region by steroid hormones. Fournal of Molecular Endocrinology 22 313-325.

Khorasanizadeh S \& Rastinejad F 2001 Nuclear-receptor interactions on DNA-response elements. Trends in Biochemical Sciences 26 384-390.

Klein-Hitpass L, Tsai SY, Greene GL, Clark JH, Tsai MJ \& O'Malley BW 1989 Specific binding of estrogen receptor to the estrogen response element. Molecular and Cellular Biology 9 43-49.

Lee KC \& Lee Kraus W 2001 Nuclear receptors, coactivators and chromatin: new approaches, new insights. Trends in Endocrinology and Metabolism 12 191-197.

Lieberman BA, Bona BJ, Edwards DP \& Nordeen SK 1993 The constitution of a progesterone response element. Molecular Endocrinology 7 515-527.

Lombes M, Binart N, Oblin ME, Joulin V \& Baulieu EE 1993 Characterization of the interaction of the human mineralocorticosteroid receptor with hormone response elements. Biochemical fournal 292 577-583.

McKenna NJ \& O'Malley BW 2002 Minireview: nuclear receptor coactivators-an update. Endocrinology 143 2461-2465.

Nelson CG, Hendy SC, Shukin RJ, Cheng H, Bruchovsky N, Koop BF \& Rennie PS 1999 Determinants of DNA sequence specificity of the androgen, progesterone, and glucocorticoid receptors: evidence for differential steroid receptor response elements. Molecular Endocrinology 13 2090-2107.

Nordeen SK, Suh BJ, Kuhnel B \& Hutchison CD 1990 Structural determinants of a glucocorticoid receptor recognition element. Molecular Endocrinology 4 1866-1873.

Quandt K, Frech K, Karas H, Wingender E \& Werner T 1995 MatInd and MatInspector: new fast and versatile tools for detection of consensus matches in nucleotide sequence data. Nucleic Acids Research 23 4878-4884.

Rennie PS, Bruchovsky N, Leco KJ, Sheppard PC, McQueen SA, Cheng H, Snoek R, Hamel A, Bock ME, MacDonald BS et al. 1993 Characterization of two cis-acting DNA elements involved in the androgen regulation of the probasin gene. Molecular Endocrinology 7 23-36.

Riegman PH, Vlietstra RJ, van der Korput JA, Brinkmann AO \& Trapman J 1991 The promoter of the prostate-specific antigen gene contains a functional androgen responsive element. Molecular Endocrinology 5 1921-1930.

Roche PJ, Hoare SA \& Parker MG 1992 A consensus DNA-binding site for the androgen receptor. Molecular Endocrinology 6 2229-2235.

Rusconi S \& Yamamoto KR 1987 Functional dissection of the hormone and DNA binding activities of the glucocorticoid receptor. EMBO foumal 6 1309-1315.

Sambrook J \& Russell DW 2001 Molecular Cloning a laboratory manual, 3rd edn, Cold Spring Harbor, NY, USA: Cold Spring Harbor Laboratory Press.

Scheller A, Hughes E, Golden KL \& Robins DM 1998 Multiple receptor domains interact to permit, or restrict, androgen-specific gene activation. Fournal of Biological Chemistry 273 24216-24222.

Schuurmans AL, Bolt J, Voorhorst MM, Blankenstein RA \& Mulder E 1988 Regulation of growth and epidermal growth factor receptor levels of LNCaP prostate tumor cells by different steroids. International Fournal of Cancer 42 917-922.

Strahle U, Boshart M, Klock G, Stewart F \& Schutz G 1989 Glucocorticoid- and progesterone-specific effects are determined by differential expression of the respective hormone receptors. Nature 339 629-632.

Thornton JW 2001 Evolution of vertebrate steroid receptors from an ancestral estrogen receptor by ligand exploitation and serial genome expansions. PNAS 98 5671-5676.

Verrijdt G, Schoenmakers E, Alen P, Haelens A, Peeters B, Rombauts W \& Claessens F 1999 Androgen specificity of a response unit upstream of the human secretory component gene is mediated by differential receptor binding to an essential androgen response element. Molecular Endocrinology 13 1558-1570.

Verrijdt G, Schoenmakers E, Haelens A, Peeters B, Verhoeven G, Rombauts W \& Claessens F 2000 Change of specificity mutations in androgen-selective enhancers. Evidence for a role of differential DNA binding by the androgen receptor. Fournal of Biological Chemistry 275 12298-12305.

Wood JR, Likhite VS, Loven MA \& Nardulli AM 2001 Allosteric modulation of estrogen receptor conformation by different estrogen response elements. Molecular Endocrinology 15 1114-1126.

Young CY, Montgomery BT, Andrews PE, Qui SD, Bilhartz DL \& Tindall DJ 1991 Hormonal regulation of prostate-specific antigen messenger RNA in human prostatic adenocarcinoma cell line LNCaP. Cancer Research 51 3748-3752.

Received 4 June 2004

Accepted 5 July 2004 
